www.nature.com/ejhg

\title{
The importance of plasma apolipoprotein $E$ concentration in addition to its common polymorphism on inter-individual variation in lipid levels: results from Apo Europe
}

\author{
Nadia Haddy ${ }^{1}$, Dirk De Bacquer ${ }^{2}$, Marianne Mansour Chemaly ${ }^{1}$, Mickaël Maurice ${ }^{1}$, \\ Christian Ehnholm ${ }^{3}$, Alun Evans ${ }^{4}$, Susanna Sans ${ }^{5}$, Maria do Carmo Martins ${ }^{5,6}$, \\ Guy De Backer ${ }^{2}$, Gérard Siest ${ }^{1}$ and Sophia Visvikis*,1
}

${ }^{1}$ INSERM U 525 Equipe 4, 30 rue Lionnois, 54000 Nancy, France; ${ }^{2}$ Department of Public Health, University of Gent, Gent, Belgium; ${ }^{3}$ National Public Health Institute, Department of Biochemistry, Helsinki, Finland; ${ }^{4}$ Department of Epidemiology and Public Health, Queen's University Belfast, UK; ${ }^{5}$ Programa Cronicat, Instituto National de Saude, Lisbon, Portugal; ${ }^{6}$ Unidade de Quimica Clinica, Instituto National de Saude, Lisbon, Portugal

Interindividual variation in the concentration of plasma lipids which are associated with coronary artery disease (CAD) risk is determined by a combination of genetic and environmental factors. This study investigates the effects of apoE genotype and plasma concentration on cholesterol and triglycerides (TG) levels in subjects from five countries: Finland, France, Northern Ireland, Portugal, and Spain. Age and sex significantly influenced serum cholesterol, TG and apoE concentrations. The age effect differs in males and females. The allele frequencies of the apoE gene, one of the most widely studied CAD susceptibility genes, were determined: the $\varepsilon 2$ allele frequency and the apoE concentration showed a north -south increasing gradient while the $\varepsilon 4$ allele frequency showed the reverse. ApoE plays an important role in lipid metabolism. Total cholesterol and TG concentrations were significantly dependent on apoE genotype in both sexes. These differences in lipids between genotypes were more pronounced when plasma apoE concentrations were taken into account.

European Journal of Human Genetics (2002) 10, 841 - 850. doi:10.1038/sj.ejhg.5200864

Keywords: cardiovascular risk; ApoEurope; apoE polymorphism; apoE concentration; inter-individual lipid levels variation

\section{Introduction}

CAD is one of the main causes of mortality and morbidity in developed countries. Several major risk factors for atherosclerosis have been identified; age, gender, hypercholesterolaemia, hypertriglyceridaemia, hypertension, diabetes and smoking.

Genetic factors in combination with environment play an important role in the etiology of CAD. ${ }^{1}$ It is known that

*Correspondence: S Visvikis, INSERM, U525 Equipe 4, 30 rue Lionnois, 54000 Nancy, France; Tel: +33 03831788 34; Fax: +33 03833213 22; E-mail: Sophie.visvikis@cmp.u-nancy.fr

Received 15 January 2002; revised 31 May 2002; accepted 28 June 2002 the genetic polymorphism of apolipoprotein $\mathrm{E}$ (apoE) modulates lipoprotein metabolism and thereby influences CAD risk factors. ApoE is probably the most studied susceptibility gene for atherosclerosis and CAD. There are three common alleles of the apoE gene $(\varepsilon 2, \varepsilon 3$ and $\varepsilon 4)$. This polymorphism results in six genotypes, three heterozygote $\varepsilon 3 / \varepsilon 2, \varepsilon 3 / \varepsilon 4, \varepsilon 4 / \varepsilon 2$ and three homozygote genotypes $\varepsilon 2 / \varepsilon 2$, $\varepsilon 3 / \varepsilon 3$ and $\varepsilon 4 / \varepsilon 4$. $^{2}$ The alleles encode isoforms of apoE, which differ in terms of their interaction with cell surface receptors, and catabolism of apoB-containing lipoproteins.

In the population at large, the $\varepsilon 2$ allele is associated with lower and the $\varepsilon 4$ with higher total cholesterol than the $\varepsilon 3$ allele. In some studies the $\varepsilon 2$ and the $\varepsilon 4$ alleles have been 
reported to be associated with high triglycerides levels. ${ }^{3-5}$ Nevertheless the role of apoE polymorphism in neither cholesterol nor triglycerides metabolism has been fully elucidated. It also influences the plasma concentration of $\operatorname{apoE}^{6}$ and apoB. The serum apoE concentration is highest in $\varepsilon 2$ carriers and lowest in $\varepsilon 4$ carriers. ${ }^{7}$ The plasma apoB concentration shows the opposite pattern, it is lowest in subjects heterozygous for apoE 2 and highest in E4/4 subjects. $^{8}$

Several studies have demonstrated that the apoE polymorphism is associated with the risk of CAD. ${ }^{9}$ However, the antiatherogenic effect of apoE is not entirely mediated through lipid metabolism, as it may also have a local effect on the arterial wall and on cellular regulation. The purpose of this study was to investigate the role of apoE genotypes and plasma concentration as risk markers for disease. Our investigations have been realised, thanks to the ApoEurope project.

The objective of the ApoEurope project is to establish the usefulness of apoE genotype and concentration in health and diseases. The specific objectives are: (1) to determine the factors affecting interindividual variation in apoE plasma concentration, particularly the role of apoE genetic polymorphism; (2) To study the distribution of apoE genotype/apoE plasma concentration across different European populations; (3) To evaluate, in case-control studies, the role of apoE plasma concentration together with apoE genotype as risk factors for: coronary artery disease and alzheimer disease. More details on ApoEurope project are given by Schiele et al. ${ }^{7}$

Our study presents a useful element for going deeper in the different steps of the ApoEurope project by investigating the combined usefulness of the apoE genotype and concentration.

\section{Materials and methods}

\section{Subjects}

Subjects from different geographic regions of Europe were selected for participation in the ApoE-Europe project (Part I). More details on ApoEurope project are given by Schiele et al. ${ }^{7}$ Five centres, Helsinki (Finland), Belfast (Northern Ireland), Nancy (France), Lisbon (Portugal), and Barcelona (Spain) participated. Persons taking lipidlowering drugs were excluded. The total number of subjects participating was 6207; consisting of 3267 men and 2940 women aged between 25-64 years. All participants were considered as being free from serious and/or chronic illnesses (Alzheimer disease, CHD ...) at the time of the recruitment. Each participant filled specific questionnaires concerning their state of health. Recruitment was done according to the ethic rules of each country participating in the study: when needed each participant gave their informed consent for participating in the different studies, which were approved by the ethic committee of each centre.
In Finland, the subjects were a sub-sample of the third Finmonica ${ }^{10}$ risk factor survey carried out from JanuaryMarch 1992. These participants were men and women aged 45-64 years. In Northern Ireland, the participants were male volunteers aged between 30-54 years from a large Belfast based work-force, and included all grades of staff from manual to clerical and administrative workers. In France, the participants were derived from the Stanislas ${ }^{11}$ cohort, a sample from the general population living in the Vosges region and the centre of Meurthe-etMoselle. One thousand and six families consisting of two parents and at least two of their biological children were selected. All participants were of European origin. They were considered as being free from serious and/or chronic illnesses. The parents included were aged from 25 to 64 years. In Portugal, the sample consisted of those attending different laboratories of the National Institute of Health of Lisbon, aged between 25 and 64 years. Subjects were invited daily in a random fashion, from those who were present at the blood collection from 8.30 to $10.00 \mathrm{am}$. AIDS seropositives persons were excluded. All participants were considered healthy. In Spain, the population base was the Monica ${ }^{12}$ area of Barcelona, which had a total population of over 1000000 inhabitants. The area is representative of the whole region of Catalonia. The sample, stratified by age and sex, was drawn from the municipal population registers. The subjects selected were aged from 25 to 64 years.

\section{Blood samples}

In Finland, subjects were requested to fast for 4 hours before taking the blood samples, which were then centrifuged at $1400 \mathrm{~g}$ for $30 \mathrm{~min}$ at room temperature. Serum was divided in $0.5 \mathrm{ml}$ aliquots before freezing; samples were kept at $-70^{\circ} \mathrm{C}$ until analysed. In Northern Ireland, $20 \mathrm{ml}$ of venous blood was collected after a $6 \mathrm{~h}$ fast. Ten $\mathrm{ml}$ was anticoagulated with EDTA and $10 \mathrm{ml}$ allowed to clot at room temperature in the dark. In France, blood samples were collected after an overnight fast, either in EDTA for DNA preparation or in vacutainer tubes containing a gel for serum separation (Becton Dickinson). Blood was centrifuged promptly at $1000 \mathrm{~g}$ for $15 \mathrm{~min}$ at room temperature for serum and buffy coat preparation. The sera and buffy coats were stored at $-196^{\circ} \mathrm{C}$. In Spain, blood was collected after an overnight fast (10-12 h) in vacutainer tubes without anticoagulant. Blood was centrifuged at $+4^{\circ} \mathrm{C}$ at $2500 \mathrm{~g}$ for $15-20 \mathrm{~min}$. Samples were transported at $+4^{\circ} \mathrm{C}$ to the central laboratory where they were stored at $-80^{\circ} \mathrm{C}$. In Portugal, after an overnight fast, blood was collected in vacutainer tubes, one containing EDTA for DNA extraction and the other containing a separating gel without anticoagulant for serum separation. Samples were stored at $-70^{\circ} \mathrm{C}$.

The designs of blood sampling and storage conditions used in the different centres are summarised in Table 1. 
Table 1 Design of blood sampling and storage conditions used in the five centres

\begin{tabular}{|c|c|c|c|c|c|}
\hline Centres & Finland & Northern Ireland & France & Spain & Portugal \\
\hline \multicolumn{6}{|l|}{ Sampling } \\
\hline Number & 2037 & 672 & 1871 & 1009 & 618 \\
\hline Sex & Men and women & Men & Men and women & Men and women & Men and women \\
\hline Fasting & $\geqslant 4 \mathrm{~h}$ & $\geqslant 6 \mathrm{~h}$ & $12 \mathrm{~h}$ & $12 \mathrm{~h}$ & $12 \mathrm{~h}$ \\
\hline Posture & Sitting & Sitting & Supine & Sitting & Supine \\
\hline Period & $1992-1992$ & $1994-1995$ & $1993-1995$ & $1993-1994$ & $1996-1997$ \\
\hline \multicolumn{6}{|l|}{ Storage } \\
\hline Duration (up to) & 5.5 years & 2.6 years & 1.5 years & $3-4$ years & 6 months \\
\hline Temperature & $-70^{\circ} \mathrm{C}$ & $-80^{\circ} \mathrm{C}$ & $-196^{\circ} \mathrm{C}$ & $-80^{\circ} \mathrm{C}$ & $-70^{\circ} \mathrm{C}$ \\
\hline
\end{tabular}

\section{Lipid measurements}

The measurements of the different parameter concentrations were done in France. Specific tests showed that fresh and frozen samples have no significant differences on lipid levels. Storing at -70 to $-196^{\circ} \mathrm{C}$ temperatures did not affect the samples.

Total cholesterol and triglycerides were measured using enzymatic methods on an automated analyser (Roche Diagnostics). ApoE concentrations were determined by immunoturbidimetry according to the manufacturer's recommendations, using a kit from Daiichi (number 114861). ${ }^{7}$ Sera were analysed without pre-treatment and, when apoE concentration exceeded $100 \mathrm{mg} / \mathrm{l}$, diluted in double-distilled water.

\section{Apolipoprotein E genotyping and phenotyping}

DNA extraction from whole blood or buffy coat was performed using a salting-out procedure. ${ }^{13}$ ApoE genotype was determined by PCR amplification and subsequent digestion with HhaI restriction enzyme, as described by Hixson and Vernier. ${ }^{14}$ ApoE phenotyping was determined by isoelectrofocusing and immunoblotting.

\section{Statistical methods}

The distribution of the apoE alleles was tested for HardyWeinberg equilibrium by $\chi^{2}$ testing. Adjustment of mean cholesterol and triglycerides levels for age and centre was done by analysis of covariance. Because of the skewness of the triglycerides distribution, logarithmic transformations were applied in order to meet the model assumptions. Multiple regression analyses were performed to study the simultaneous independent contribution of the apoE polymorphism and concentrations with age, body mass index, current smoking and contraceptive pill use as covariates. In view of the non-linear effect of age on cholesterol levels, a quadratic term for age was introduced in the models. Regression assumptions were visually checked through the Pearson residuals. An a priori level of $\alpha=0.05$ was chosen to indicate statistical significance. All analyses were performed using SAS software (version 6.12).

\section{Results}

Table 2 presents the observed distribution of apoE genotypes among the participants by centre separately for men and women. The distributions of the apoE alleles were in Hardy-Weinberg equilibrium. The frequencies of $\varepsilon 2$ and $\varepsilon 4$ alleles showed a significant difference across centres. As reported before, ${ }^{7}$ the $\varepsilon 2$ allele frequency followed a northsouth increasing gradient while the $\varepsilon 4$ allele showed the reverse.

In Table 3, the distributions of plasma cholesterol, triglycerides and apoE concentrations are shown by age group, centre and apoE genotype for men and women separately. The total cholesterol levels generally rose with age but seemed to level off after the age of 54 years in both sexes. The influence of age on triglycerides concentrations was fairly linear. We observed a sex-differential effect of age on mean apoE concentrations as in men apoE concentrations are leveled off after the age of 45 years, whereas they are continuously rising with age in women.

In order to correct for differences in the age distributions, the means for the several centres and genotypes, as well as the overall sex-specific means, were age-adjusted. In general, total cholesterol and triglycerides levels were higher in men than in women. Also, there was a tendency towards higher average apoE concentrations in men compared to women. As expected, the subjects from the northern countries: Finland, Northern Ireland and France, had higher mean cholesterol concentrations than those from the Southern countries: Portugal and Spain, a consistent observation in both sexes. A geographical trend among the five populations was less obvious for serum triglycerides, with the lowest age-adjusted averages in French men and women and the highest levels in Northern-Ireland and Spain. For both sexes, there was a clear tendency for higher mean apoE concentrations in the southern centres. This trend seemed to be broken only by the high apoE concentrations in men from Northern Ireland.

We observed the lowest cholesterol concentrations among $\varepsilon 2$ carriers, while the $\varepsilon 4$ allele seems to be associated with higher cholesterol levels. The $\varepsilon 4 / \varepsilon 4$ homozygotes had the highest mean concentration of cholesterol in both sexes 
Table 2 Frequency of apoE genotype and apoE allele by centre and sex

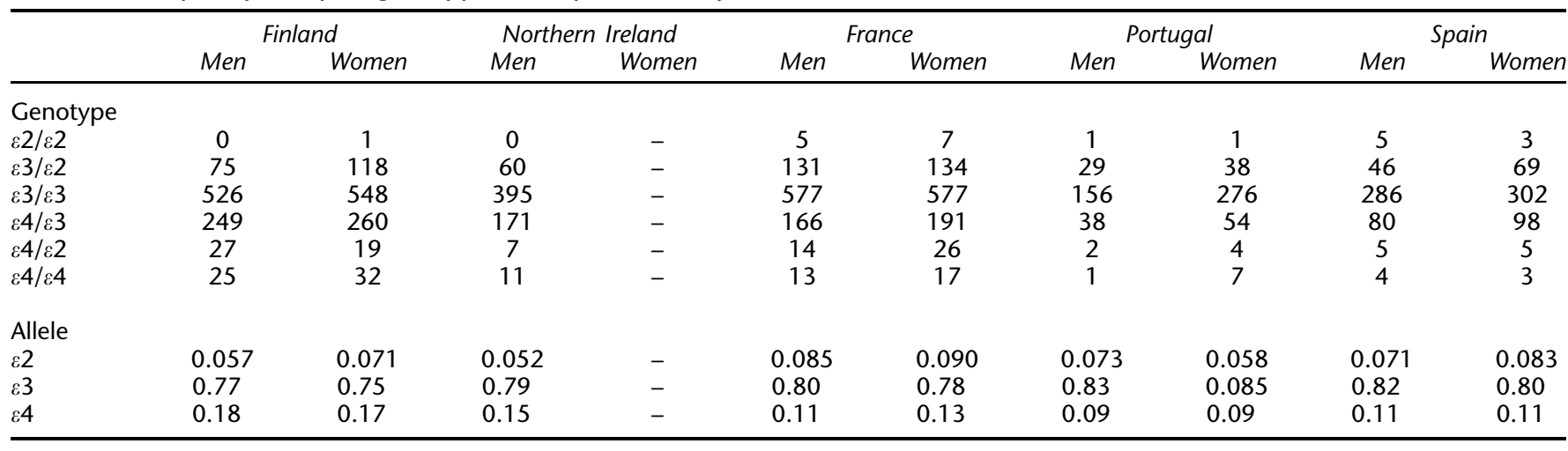

Table 3 Mean total cholesterol, triglycerides and apoE concentrations by sex, age and centre

\begin{tabular}{|c|c|c|c|c|}
\hline & $\mathrm{n}$ & $\begin{array}{c}\text { Total } \\
\text { cholesterol } \\
(\mathrm{mmol} / \mathrm{l})\end{array}$ & $\begin{array}{c}\text { Triglycerides } \\
(\mathrm{mmol} / \mathrm{l})\end{array}$ & $\begin{array}{c}\text { ApoE } \\
\text { concentration } \\
(\mathrm{mg} / \mathrm{l})\end{array}$ \\
\hline \multicolumn{5}{|l|}{ Men } \\
\hline $25-34$ years & 378 & 5.32 & 1.11 & 38.5 \\
\hline $35-44$ years & 1174 & 5.88 & 1.25 & 40.7 \\
\hline $45-54$ years & 1064 & 6.00 & 1.34 & 40.8 \\
\hline $55-64$ years & 651 & 5.84 & 1.33 & 40.2 \\
\hline Finland & 970 & 5.82 & 1.28 & 36.9 \\
\hline $\mathrm{N}$-Ireland & 672 & 6.00 & 1.49 & 43.0 \\
\hline France & 915 & 6.00 & 1.14 & 39.6 \\
\hline Portugal & 232 & 5.59 & 1.24 & 44.3 \\
\hline Spain & 478 & 5.54 & 1.30 & 44.1 \\
\hline$\varepsilon 2 / \varepsilon 2$ & 11 & 5.59 & 1.44 & 73.9 \\
\hline$\varepsilon 3 / \varepsilon 2$ & 341 & 5.50 & 1.30 & 47.3 \\
\hline$\varepsilon 3 / \varepsilon 3$ & 1940 & 5.84 & 1.23 & 39.6 \\
\hline$\varepsilon 4 / \varepsilon 3$ & 704 & 6.04 & 1.35 & 38.9 \\
\hline$\varepsilon 4 / \varepsilon 2$ & 45 & 5.82 & 1.43 & 46.8 \\
\hline$\varepsilon 4 / \varepsilon 4$ & 54 & 6.06 & 1.35 & 37.0 \\
\hline All men & 3267 & 5.85 & 1.28 & 40.4 \\
\hline \multicolumn{5}{|l|}{ Women } \\
\hline $25-34$ years & 292 & 5.05 & 0.83 & 36.0 \\
\hline $35-44$ years & 921 & 5.39 & 0.81 & 37.0 \\
\hline $45-54$ years & 991 & 5.63 & 0.95 & 38.6 \\
\hline $55-64$ years & 736 & 5.20 & 1.15 & 42.6 \\
\hline Finland & 1067 & 5.59 & 0.94 & 35.6 \\
\hline N-Ireland & 0 & - & - & - \\
\hline France & 956 & 5.87 & 0.86 & 38.1 \\
\hline Portugal & 386 & 5.54 & 0.99 & 42.7 \\
\hline Spain & 531 & 5.39 & 1.01 & 44.3 \\
\hline$\varepsilon 2 / \varepsilon 2$ & 12 & 4.52 & 1.05 & 59.4 \\
\hline$\varepsilon 3 / \varepsilon 2$ & 359 & 5.34 & 1.08 & 45.3 \\
\hline$\varepsilon 3 / \varepsilon 3$ & 1703 & 5.60 & 1.10 & 38.4 \\
\hline$\varepsilon 4 / \varepsilon 3$ & 603 & 5.88 & 1.04 & 35.8 \\
\hline$\varepsilon 4 / \varepsilon 2$ & 54 & 5.50 & 1.15 & 47.0 \\
\hline$\varepsilon 4 / \varepsilon 4$ & 59 & 6.02 & 1.02 & 31.6 \\
\hline All women & 2940 & 5.64 & 0.94 & 38.8 \\
\hline
\end{tabular}

Note: means by centre, apoE genotype and sex are age-adjusted.
(6.06 $\mathrm{mmol} / \mathrm{l}$ in men and $6.02 \mathrm{mmol} / \mathrm{l}$ in women) whereas the $\varepsilon 2 / \varepsilon 2$ homozygotes had the lowest levels in women $(4.52 \mathrm{mmol} / \mathrm{l})$, and nearly so in men $(5.59 \mathrm{mmol} / \mathrm{l})$. Heterozygosity $(\varepsilon 3 / \varepsilon 2, \quad \varepsilon 3 / \varepsilon 4$ and $\varepsilon 2 / \varepsilon 4)$ was associated with intermediate concentrations. As the apoE concentration proved to be highly allele-dependent, as seen in Table 3, this association between apoE polymorphism and cholesterol levels may be confounded by the apoE concentration. Therefore, mean cholesterol levels were additionally adjusted for the apoE concentration. As can be seen in Figure 1a, the impact of the apoE polymorphism on total cholesterol levels was even more striking when apoE concentrations were taken into account. After adjusting for age and centre only, the mean cholesterol levels were only moderately different between the apoE genotypes. However, with additional adjustment for the apoE concentration, the differences became huge, proving the crucial confounding impact of the apoE concentration in interpreting the role of the apoE polymorphism in explaining the inter-individual variability in cholesterol levels. In order to explain the variability of the cholesterol concentrations in more detail, results of fitting three nested multiple regression models for both sexes are presented in Table 4 . Age was modeled as a linear and quadratic effect because of its curvilinear relation to total cholesterol levels. Introducing the apoE concentrations in the model had a fundamental impact on the percentage of explained variance (model $\mathrm{C}$ ). The apoE polymorphism alone (model B) was responsible only for a moderate $2 \%$ increase in explained variance of cholesterol levels in both men and women. Moreover, these results confirm the important role of the apoE concentrations in interpreting differences in mean cholesterol levels between genotypes. For example, without additional adjustment for apoE concentration, in men the differences in mean cholesterol between the $2 / 2$ and $3 / 3$ and between $4 / 4$ and $3 / 3$ genotypes were $-0.155 \mathrm{mmol} / \mathrm{l}$ and $+0.166 \mathrm{mmol} / \mathrm{l}$ respectively (both not significant, model B). However, additional correction for the apoE concentration changed these differences to respec- 
Table 4 Estimated regression coefficients in several models for total cholesterol

\begin{tabular}{|c|c|c|c|c|c|c|}
\hline & $\begin{array}{c}\text { Model } A \\
\beta\end{array}$ & $\begin{array}{c}\text { Men } \\
\text { Model B } \\
\beta\end{array}$ & $\begin{array}{c}\text { Model C } \\
\beta\end{array}$ & $\begin{array}{c}\text { Model } A \\
\beta\end{array}$ & $\begin{array}{c}\text { Women } \\
\text { Model } B \\
\beta\end{array}$ & $\begin{array}{c}\text { Model } C \\
\beta\end{array}$ \\
\hline Age & $0.194^{c}$ & $0.192^{c}$ & $0.124^{c}$ & $-0.048^{a}$ & $-0.047^{a}$ & -0.034 \\
\hline $\mathrm{BMI}$ & $0.036^{c}$ & $0.035^{c}$ & -0.004 & $0.020^{c}$ & $0.021^{c}$ & 0.001 \\
\hline Smoking & $0.134^{\mathrm{b}}$ & $0.140^{\mathrm{b}}$ & $0.103^{b}$ & 0.075 & 0.071 & 0.068 \\
\hline Contraceptive drugs use & - & - & - & 0.012 & 0.044 & $0.312^{c}$ \\
\hline Finland & $-0.246^{c}$ & $-0.293^{c}$ & $-0.124^{a}$ & $-0.347^{c}$ & $-0.380^{c}$ & -0.208 \\
\hline N-Ireland & -0.038 & -0.073 & $-0.225^{c}$ & - & - & - \\
\hline Portugal & $-0.394^{c}$ & $-0.399^{c}$ & $-0.612^{c}$ & $-0.388^{c}$ & $-0.396^{c}$ & -0.581 \\
\hline Spain & $-0.529^{c}$ & $-0.546^{c}$ & $-0.714^{c}$ & $-0.536^{c}$ & $-0.514^{c}$ & -0.699 \\
\hline \multicolumn{7}{|l|}{ ApoE genotype (vs 3/3) } \\
\hline $2 / 2$ & - & -0.155 & $-1.365^{c}$ & - & $-1.028^{c}$ & $-1.810^{\circ}$ \\
\hline Ln(ApoE concentration) & - & - & $1.972^{\mathrm{C}}$ & - & - & $1.750^{\circ}$ \\
\hline $\mathrm{R}^{2}$ & $8 \%$ & $10 \%$ & $34 \%$ & $18 \%$ & $21 \%$ & $38 \%$ \\
\hline
\end{tabular}

${ }^{\mathrm{a}} \mathrm{P}<0.05{ }^{\mathrm{b}} \mathrm{P}<0.01{ }^{\mathrm{c}} \mathrm{P}<0.0001$. Model $\mathrm{A}$ : includes age, age ${ }^{2}, \mathrm{BMI}$, smoking, contraceptive drugs use for women, and centre. Model $\mathrm{B}$ : model AtapoE genotype. Model C: model $\mathrm{B}+\ln \left(\right.$ apoE concentration). $\beta$ : estimated regression coefficient. $\mathrm{R}^{2}$ : \% explained variance in cholesterol levels.

tively $-1.365 \mathrm{mmol} / \mathrm{l}(2 / 2$ vs $3 / 3)$ and $+0.284 \mathrm{mmol} / \mathrm{l}(4 / 4$ vs $3 / 3$ ), both being statistically significant (model C). From the estimated centre-specific regression coefficients we also can conclude that differences in cholesterol distributions between centres were altered when the apoE polymorphism and concentration are taken into account. Interestingly, the effect of BMI on cholesterol levels dropped in both sexes when adding the apoE concentration to the model. In women, the impact of contraceptive pill use on total cholesterol levels was 10-fold higher when the apoE concentrations were taken into account.

We also studied the variability of triglycerides levels as a function of the apoE genotype. We found very similar results (Table 5), as differences in mean triglycerides between apoE genotypes were much more pronounced when the apoE concentration was considered (Figure 1b). In both sexes, additional correction for the apoE concentration resulted in a decrease in mean triglycerides levels in the presence of the $\varepsilon 2$ allele and an increase in $\varepsilon 4$ subjects. The triglycerides concentrations of the $\varepsilon 2 / \varepsilon 2$ genotype carriers decreased in men from 1.52 to $0.47 \mathrm{mmol} / \mathrm{l}$ and in women a decrease was noted from 1.07 to $0.70 \mathrm{mmol} / \mathrm{l}$. In $\varepsilon 4 / \varepsilon 4$ homozygotes, the triglycerides concentrations rose from 1.34 to $1.39 \mathrm{mmol} / \mathrm{l}$ in men and from 1.02 to $1.12 \mathrm{mmol} / \mathrm{l}$ in women (Figure 1b). Biological factors such as age, BMI, tobacco consumption and geographic location, explained 14 and 23\%, respectively of inter-individual variability of triglycerides concentrations in men and women. Adding in the apoE genotype only explained an extra $1 \%$ in men and women. The apoE concentration had a supplementary contribution resulting in explained variances of $51 \%$ in men and $39 \%$ in women.

\section{Discussion}

Adverse levels of serum lipids are predictive of CAD. In the Program On the Surgical Control of the Hyperlipidaemias $(\mathrm{POSCH}){ }^{15}$ Scandinavian Simvastatin Survival Study (4S) ${ }^{16}$ Cholesterol And Recurrent Events (CARE) ${ }^{17}$ and West of Scotland Coronary Prevention Study studies (WOSCOPS), ${ }^{18}$ total plasma cholesterol and triglycerides values were positively correlated with cardiovascular risk.

The understanding of the inter-individual variabilities of cholesterol and triglycerides plasma concentrations is useful for the prediction and for the treatment of these diseases. In the majority of cases, an individuals risk of developing $\mathrm{CAD}$ is the consequence of complex interactions of many genetic and environmental factors. ${ }^{19}$

In our study, age and sex significantly influence serum cholesterol, triglycerides and apoE concentrations. We found lower mean values in women than in men. Age effects differed between males and females beyond 45 years; cholesterol, TG and apoE concentrations were quite steady in men but continue to increase with age in women. Gender-specific factors, such as hormonal status, could be responsible for these gender differences. Sex hormones are known to have multiple effects on lipoprotein metabolism. The shortened retention time of apoE in very low density 
Table 5 Estimated regression coefficient in several models for total triglycerides

\begin{tabular}{|c|c|c|c|c|c|c|}
\hline & $\begin{array}{c}\text { Model } A \\
\beta\end{array}$ & $\begin{array}{c}\text { Men } \\
\text { Model B } \\
\beta\end{array}$ & $\begin{array}{c}\text { Model C } \\
\beta\end{array}$ & $\begin{array}{c}\text { Model } A \\
\beta\end{array}$ & $\begin{array}{c}\text { Women } \\
\text { Model B } \\
\beta\end{array}$ & $\begin{array}{c}\text { Model C } \\
\beta\end{array}$ \\
\hline Age & $0.045^{c}$ & $0.044^{c}$ & 0.016 & -0.017 & $-0.019^{a}$ & -0.012 \\
\hline $\mathrm{Age}^{2}$ & $-0.00045^{c}$ & $-0.00045^{c}$ & -0.00016 & $0.00031^{b}$ & $0.00032^{c}$ & $0.00020^{\mathrm{a}}$ \\
\hline $\mathrm{BMI}$ & $0.049^{c}$ & $0.049^{c}$ & $0.029^{c}$ & $0.036^{c}$ & $0.036^{c}$ & $0.028^{c}$ \\
\hline Smoking & $0.135^{\mathrm{b}}$ & $0.136^{c}$ & $0.111^{\mathrm{c}}$ & $0.106^{c}$ & $0.106^{c}$ & $0.104^{c}$ \\
\hline Contraceptive drugs use & - & - & - & $0.257^{c}$ & $0.259^{c}$ & $0.362^{c}$ \\
\hline \multicolumn{7}{|l|}{ Centre (vs France) } \\
\hline Finland & 0.052 & 0.053 & $0.125^{c}$ & 0.038 & 0.035 & $0.105^{c}$ \\
\hline Portugal & 0.077 & $0.080^{\mathrm{a}}$ & -0.042 & $0.113^{c}$ & $0.122^{c}$ & 0.035 \\
\hline Spain & $0.08^{\mathrm{a}}$ & $0.084^{b}$ & -0.023 & $0.104^{c}$ & $0.113^{c}$ & 0.029 \\
\hline \multicolumn{7}{|l|}{ ApoE genotype (vs 3/3) } \\
\hline $2 / 2$ & - & 0.245 & $-0.842^{c}$ & - & 0.190 & -0.202 \\
\hline $3 / 2$ & - & 0.058 & $-0.139^{c}$ & - & 0.017 & $-0.122^{c}$ \\
\hline $4 / 3$ & - & $0.081^{\mathrm{b}}$ & $0.078^{c}$ & - & $0.070^{\mathrm{b}}$ & $0.106^{c}$ \\
\hline $4 / 2$ & - & 0.095 & -0.045 & - & $0.230^{c}$ & 0.045 \\
\hline $4 / 4$ & - & 0.012 & 0.054 & - & $0.116^{\mathrm{a}}$ & $0.218^{c}$ \\
\hline Ln(ApoE concentration) & - & - & $0.026^{c}$ & - & - & $0.019^{c}$ \\
\hline $\mathrm{R}^{2}$ & $14 \%$ & $15 \%$ & $51 \%$ & $23 \%$ & $24 \%$ & $39 \%$ \\
\hline
\end{tabular}

${ }^{\mathrm{a}} P<0.05{ }^{\mathrm{b}} P<0.01{ }^{\mathrm{c}} P<0.0001$. Model $\mathrm{A}$ : includes age, age ${ }^{2}, \mathrm{BMI}$, smoking, contraceptive drugs use for women, and centre. Model B: model $\mathrm{A}+\mathrm{apoE}$ genotype. Model $\mathrm{C}$ : model $\mathrm{B}+\ln \left(\mathrm{apoE}\right.$ concentration). $\beta$ : estimated regression coefficient. $\mathrm{R}^{2}$ : \% explained variance in cholesterol levels.

lipoprotein (VLDL) associated with the presence of oestrogen, as reported in animal studies, suggests that oestrogen influences VLDL clearance. $^{20}$

Schiele $e \mathrm{al}^{7}$ found that serum apoE concentration continued to increase in women aged over 50 years, and related this to hormonal changes at the menopause. Indeed the effect of menopause is frequently studied and is known to be a cardiovascular risk factor. ${ }^{21,22}$ The effect of sex hormones in interaction with age could explain the differences in apoE concentration between men and women observed in the literature. Indeed, in some studies it has been demonstrated that apoE concentration was higher in women, ${ }^{23}$ in others, apoE concentration was higher in $\mathrm{men}^{24}$ or even no difference between men and women was observed. ${ }^{25}$

We have shown that in northern countries (Finland, NIreland and France) women or men had mean cholesterol and triglycerides concentrations higher than those of the southern countries. One important finding suggested the existence of an increasing north-south gradient in the serum apoE concentration throughout Europe, and this has already been described by Schiele et $a .^{7}$

The frequencies of the apoE alleles differ among populations, ranging from 0.052 to 0.09 for $\varepsilon 2,0.75$ to 0.85 for $\varepsilon 3$ and 0.09 to 0.18 for $\varepsilon 4$. We observed significant difference in the distribution of the apoE alleles in the five participating centres: $\varepsilon 2$ allele follows a north-south increasing gradient but the $\varepsilon 4$ allele went in the opposite direction. This is in line with previous reports of a higher frequency of the $\varepsilon 4$ allele in northern than in southern Europe. ${ }^{4,26}$
Our study and other groups, such as Schaefer ${ }^{7,27}$ have already shown significant associations between plasma apoE concentration and apoE isoforms. Here, in a large European study, this correlation of apoE genotype with plasma apoE concentration was better defined in both men and women. This association was highly significant $(P<0.0001)$, and indicates that the apoE locus is a major factor controlling apoE concentration in plasma. ${ }^{7}$ Thus, the apoE concentration could mask the effect of genotype.

The apoE allele effect on serum cholesterol levels is similar in most populations. Differences in ethnic origin and/or lifestyle factors could explain the non-significant impact of all the genotypes on the variability of total cholesterol in Portugal (men) and in Spain (men and women). This result is in agreement with that of a Spanish team who found that the influence of apoE on plasma cholesterol was not significant in men. ${ }^{28}$ Conflicting results for triglycerides levels are found in the literature. Since triglycerides vary widely among individuals, ${ }^{3}$ this variability could mask a clear apoE genotype effect. Dallongeville et al. (1992), ${ }^{6}$ as in other studies, ${ }^{4,5}$ documented a significant association between apoE2 and apoE4 and higher triglycerides levels compared to $\varepsilon 3 / \varepsilon 3$ homozygotes.

Different apoE isoforms show different affinities to the LDL receptors, ${ }^{29}$ as reported for the apoE4 which has a higher affinity than apoE3, ${ }^{30,31}$ but the apoE2 has markedly lower binding affinity in comparison to apoE3. In addition, apoE isoforms influence the location of apoE in lipoproteins, eg apoE4 is preferentially located in VLDL, apoE3 
a

Uncorrected for apoE concentration 1 Corrected for apoE concentration

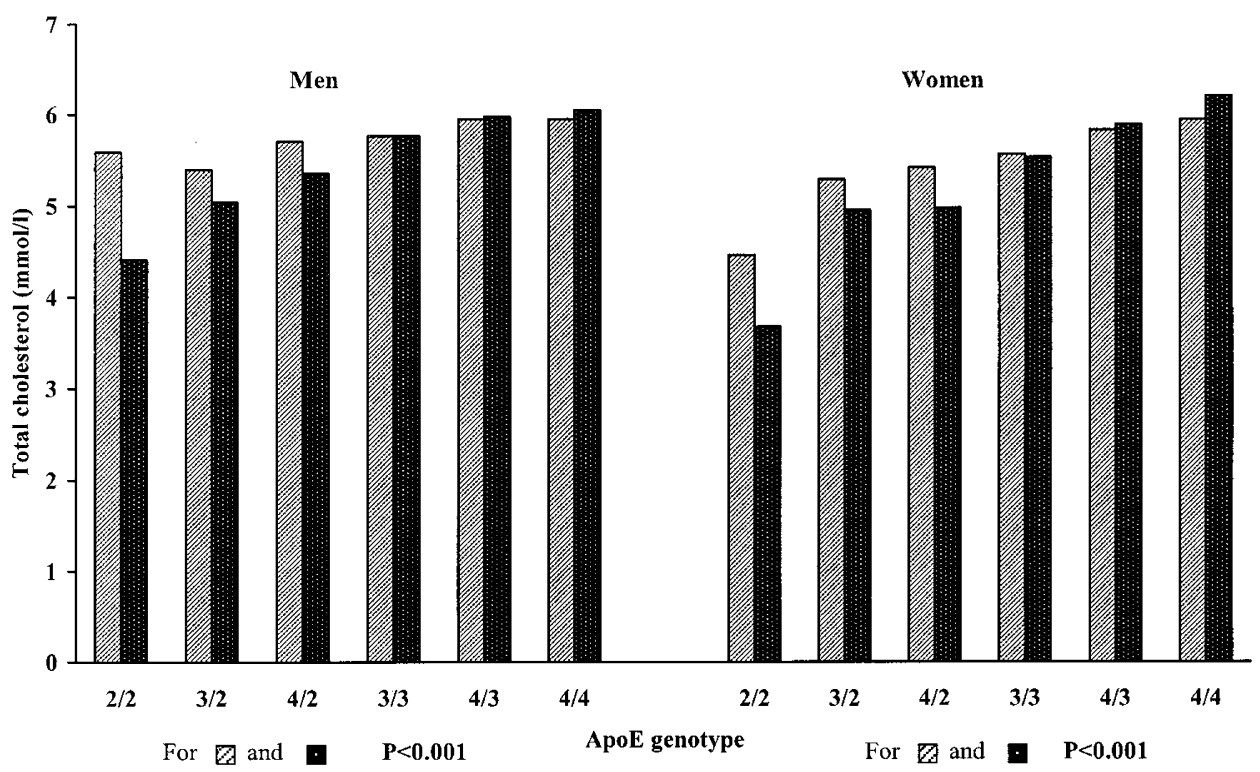

b

Uncorrected for apoE concentration E Corrected for apoE concentration

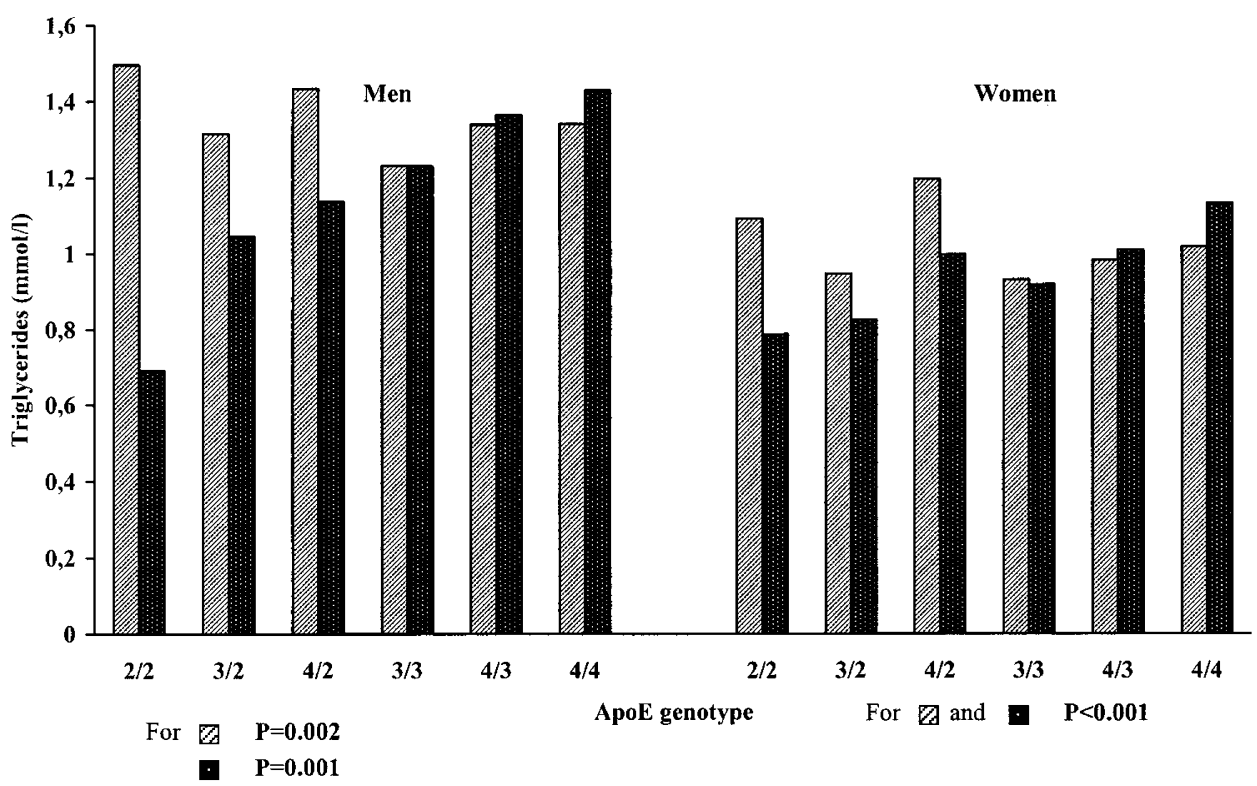

Figure 1 (a) Means of total cholesterol by apoE genotype and sex adjusted for centre and age, and before and after additional adjustment for apoE concentration. (b) Means of plasma triglycerides by apoE genotype and sex adjusted for centre and age, and before and after additional adjustment for apoE concentration.

and apoE2 in HDL. ${ }^{32}$ As a consequence, $\varepsilon 2$ has been estimated to decrease LDL cholesterol by $12.5 \%$ and HDL cholesterol by $3.1 \%$, as compared to $\varepsilon 3$. Individuals with $\varepsilon 4$, have higher concentrations of both LDL cholesterol and HDL cholesterol with estimated increases of $6.4 \%$ and $1.9 \%$, respectively. ${ }^{33}$
The inter-individual variability in cholesterol and TG levels can be explained by environmental factors (age, sex, etc...), genetic factors such as the apoE polymorphism and apoE concentration. It seems that apoE affects cholesterol levels similarly in different populations despite different allelic frequencies. ${ }^{34}$ 
Geographic location, body mass index, tobacco smoking and contraceptive pill use in women, explained 8 and $18 \%$ of the inter-individual variability of cholesterol concentration in men and women respectively. The apoE polymorphism alone was only responsible for a modest $2 \%$ higher explained variance of cholesterol levels in both sexes. The addition of the apoE concentration enabled us to explain 34 and $38 \%$ of this variability in men and in women, respectively. The combined effects of the apoE polymorphism and apoE concentration could explain the cholesterol variability better. In another study, we have also observed that apoE genotype and apoE concentration can explain $27 \%$ of the variability of the cholesterol level. ${ }^{35}$

This result, reported again in this study is as important to our knowledge as it was the first time, namely, that apoE polymorphism and concentration has been used to explain the inter-individual variability of cholesterol levels. This confirms our earlier study ${ }^{30}$ with cellular models where we showed that in addition to apoE polymorphism, apoE concentration was an important factor in determining VLDL binding to HepG2 cells surface receptors.

This explained 51 and $39 \%$ of the TG level variability in men and women, respectively. Biological factors such as age, BMI, tobacco consumption and geographic regions, explained 14 and $23 \%$ at the inter-individual variability of triglycerides concentrations in men and women respectively. ApoE polymorphism and concentration together explain triglycerides levels by $15 \%$ in men and $24 \%$ in women (taking only the apoE genotype into account) to 51 and $39 \%$ in men and in women respectively (taking the apoE genotype and concentration into account).

The total of variance of triglycerides was, 0.26 in women, and 0.68 in men; of this variance, about $22.75 \%$ women and $46.28 \%$ in men was explained by apoE concentration and apoE/LPL polymorphism. ${ }^{36}$ ApoE concentration was positively correlated with triglycerides and apoE levels explained about $42 \%$ of triglycerides variability in a Chinese CAD group. ${ }^{35}$

In conclusion, the results presented in this study are very important because they allow confirmation in large European populations of the north-south gradient of the apoE alleles frequencies and apoE concentration already described by us and others.

Most importantly, for the first time, the cholesterol and triglycerides inter-individual variability are investigated in relation with apoE polymorphism and apoE concentration, simultaneously, in large size samples and within different European populations.

Moreover, the study demonstrated not only that apoE polymorphism together with apoE concentration explained a big percentage of cholesterol and triglycerides variability but also that apoE concentration could mask the apoE polymorphism effect.

\section{Acknowledgements}

We are grateful to all the participants for their contribution in recruitment and the collection of data of the ApoEurope Project. Special thanks to all subjects who made this study possible. This work was supported by the Region Lorraine, Daiichi Pure Chemicals and, by the European Community: contract no. BMH4-1543 (DG 126SSMA) and contract S.M.\&T: MAT1-CT94-0046.

\section{References}

1 Lusis AJ: Atherosclerosis. Nature 2000; 407: 233-241.

2 Siest G, Schlenck A, Starck M, Vincent-Viry M, Schiele F, Visvikis $\mathrm{S}$ : Apolipoprotein E: Laboratory determinations and clinical interest; Rifai N, Warnick GR, Dominiczak MH (eds): Handbook of lipoprotein testing. 2nd edn. Washington: AACC Press, 2000, vol 19 , pp $401-441$.

3 Haffner SM, Stern MP, Miettinen H, Robbins D, Howard BV: Apolipoprotein E polymorphism and LDL size in a biethnic population. Arterioscler Thromb Vasc Biol 1996; 16: 1184-1188.

4 Tiret L, de Knijff P, Menzel HJ, Ehnholm C, Nicaud V, Havekes LM: ApoE polymorphism and predisposition to coronary heart disease in youths of different European populations. The EARS Study. European Atherosclerosis Research Study. Arterioscler Thromb 1994; 14: 1617 -1624.

5 Luc G, Bard JM, Arveiler D et al: Impact of apolipoprotein E polymorphism on lipoproteins and risk of myocardial infarction. The ECTIM Study. Arterioscler Thromb 1994; 14: 1412-1419.

6 Dallongeville J, Lussier-Cacan S, Davignon J: Modulation of plasma triglycerides levels by apoE phenotype: a meta-analysis. Lipid Res 1992; 33: 447-454.

7 Schiele F, De Bacquer D, Vincent-Viry M et al: Apolipoprotein E serum concentration and polymorphism in six European countries: the ApoEurope Project. Atherosclerosis 2000; 152: 475 488 .

8 Ehnholm C, Lukka M, Kuusi T, Nikkila E, Utermann G: Apolipoprotein $\mathrm{E}$ polymorphism in the Finnish population: gene frequencies and relation to lipoprotein concentrations. J Lipid Res 1986; 27: $227-235$.

9 Wilson PW, Schaefer EJ, Larson MG, Ordovas JM: Apolipoprotein E alleles and risk of coronary disease. A meta-analysis. Arterioscler Thromb Vasc Biol 1996; 16: 1250-1255.

10 Salomaa VV, Rasi VP, Vahtera EM et al: Haemostatic factors and lipoprotein (a) in three geographical areas in Finland: the Finrisk Haemostasis Study. J Cardiovasc Risk 1994; 1: $241-248$.

11 Siest G, Visvikis S, Herbeth B et al: Objectives, design and recruitment of a familial and longitudinal cohort for studying geneenvironment interactions in the field of cardiovascular risk: the Stanislas cohort. Clin Chem Lab Med 1998; 36: 35-42.

12 MONICA Project Principal Investigators: The World Health Organization MONICA Project (monitoring trends and determinants in cardiovascular disease): a major international collaboration. $J$ Clin Epidemiol 1988; 41: 105 - 114.

13 Miller SA, Dykes DD, Polesky HF: A simple salting out procedure for extracting DNA from human nucleated cells. Nucleic Acids Res 1988; 16: 1215.

14 Hixson JE, Vernier DT: Restriction isotyping of human apolipoprotein E by gene amplification and cleavage with HhaI. $J$ Lipid Res 1990; 31: 545-548.

15 Buchwald H, Boen JR, Nguyen PA, Williams SE, Matts JP: Plasma lipids and cardiovascular risk: a POSCH report, pp 221-227.

16 Miettinen TA, Gylling H, Strandberg T, Sarna S: Baseline serum cholestanol as predictor of recurrent coronary events in subgroup of Scandinavian simvastatin survival study. Finnish 4S Investigators. BMJ 1998; 316: $1127-1130$.

17 Pfeffer MA, Sacks FM, Moye LA et al: Influence of baseline lipids on effectiveness of pravastatin in the CARE Trial. Cholesterol and recurrent events. J Am Coll Cardiol 1999; 33: 125-130. 
18 West of Scotland Coronary Prevention Study Group: Influence of pravastatin and plasma lipids on clinical events in the West of Scotland Coronary Prevention Study (WOSCOPS) 1998. Circulation; 97: $1440-1445$.

19 Davignon J, Bouthillier D, Dufour R, Lussier-Cacan S: Xanthoma and atherosclerosis in the presence of normal plasma lipids. Ann Med Interne 1983; 134: 483-491.

20 Kushwaha RS, Foster DM, Barrett PH, Carey KD, Bernard MG: Metabolic regulation of plasma apolipoprotein $\mathrm{E}$ by estrogen and progesterone in the baboon (Papiosp). Metabolism 1991; 40: 93- 100 .

21 Kannel WB, Hjortland MC, McNamara PM, Gordon T: Menopause and risk of cardiovascular disease: the Framingham study. Ann Intern Med 1976; 85: 447 - 452.

22 Davis CE, Pajak A, Rywik S et al: Natural menopause and cardiovascular disease risk factors. The Poland and US Collaborative Study on Cardiovascular Disease Epidemiology. Ann Epidemiol 1994; 4: 445 - 448 .

23 Phillips NR, Havel RJ, Kane JP: Sex-related differences in the concentrations of apolipoprotein $\mathrm{E}$ in human blood plasma and plasma lipoproteins. J Lipid Res 1983; 24: 1525 - 1531.

24 Rifai N, McMurray RG, Silverman LM: The effects of the behavioral patterns on lipoprotein profile. Clin Chim Acta 1987; 169: 333 335.

$25 \mathrm{Au}$ YP, Bren ND, Kottke BA: A rapid apolipoprotein E radioimmunoassay using solid-phase staphylococcus protein. Use of pooled plasma as a secondary standard. Biochem Biophys Res Commun 1986; 138: $455-462$.

26 Gerdes LU, Klausen IC, Sihm I, Faergeman O: Apolipoprotein E polymorphism in a Danish population compared to findings in 45 other study populations around the world. Genet Epidemio 1992; 9: $155-167$.

27 Larson IA, Ordovas JM, DeLuca C, Barnard JR, Feussner G Schaefer EJ: Association of apolipoprotein (Apo)E genotype with plasma apo E levels. Atherosclerosis 2000; 148: 327 335.

28 Gomez-Coronado D, Alvarez JJ, Entrala A, Olmos JM, Herrera E, Lasuncion MA: Apolipoprotein E polymorphism in men and women from a Spanish population: allele frequencies and influence on plasma lipids and apolipoproteins. Atherosclerosis 1999; 147: $167-176$.

29 Miettinen TA: Impact of apo E phenotype on the regulation of cholesterol metabolism. Ann Med 1991; 23: 181-186.

30 Bohnet K, Pillot T, Visvikis S, Sabolovic N, Siest G: Apolipoprotein (apo) E genotype and apoE concentration determine binding of normal very low density lipoproteins to HepG2 cell surface receptors. J Lipid Res 1996; 37: 1316-1324.

31 Mamotte CD, Sturm M, Foo JI, van Bockxmeer FM, Taylor RR: Comparison of the LDL-receptor binding of VLDL and LDL from apoE4 and apoE3 homozygotes. Am J Physiol 1999; 276: E553E557.

32 Dong LM, Weisgraber KH: Human apolipoprotein E4 domain interaction. Arginine 61 and glutamic acid 255 interact to direct the preference for very low density lipoproteins. J Biol Chem 1996; 271: $19053-19057$.

33 Sing CF, Davignon J: Role of the apolipoprotein E polymorphism in determining normal plasma lipid and lipoprotein variation Am J Hum Genet 1985; 37: 268-285.

34 Siest G, Bertrand P, Qin B et al: Apolipoprotein E polymorphism and serum concentration in Alzheimer's disease in nine European centres: the ApoEurope study. ApoEurope group. Clin Chem Lab Med 2000; 38: $721-730$.

35 Xia Y, Sass C, Shen X, Siest G, Visvikis S: Associations of apolipoprotein E concentration and polymorphism with lipids and apolipoprotein levels in Chinese from Beijing and Shanghai. Clin Chem Lab Med 2000; 38: 655-659.

36 Salah D, Bohnet K, Gueguen R, Siest G, Visvikis S: Combined effects of lipoprotein lipase and apolipoprotein E polymorphisms on lipid and lipoprotein levels in the STANISLAS cohort. $J$ Lipid Res 1997; 38: 904-912.

\section{Appendix A}

Concerted action contract No BMH4-CT96-1543 (DG 12SSMA) between The European Community represented by the Commission of the European Communities ('the Commission') represented by the Director General for DG XII Science, Research and Development, or its authorised representative, and Université Henri Poincaré Nancy I, ('UNANCY.CM') established in France ('the Contractor'), represented by its authorised representative, have agreed to a concerted action called 'Apolipoprotein E: Health and disease marker in Europe'.

The Contractor: Université Henri Poincaré (Nancy I), Centre du Médicament, Nancy France: Professor Gérard Siest and Dr Sophia Visvikis.

Members of the Steering Committee: Professor G Siest and Dr S Visvikis, Nancy as coordinators, and Professor A Evans, Belfast; G De Backer, Gent; Professor J Shepherd, Glasgow.

The ApoEurope group, collaborating centres, and their associated investigators: Belgium: Department of Public Health, University of Gent, Gent: Professor Guy De Backer*, Dr Dirk De Bacquer.

Croatia: Clinical Institute of Laboratory Diagnosis, Zagreb University School of Medicine and Clinical Hospital Centre, Zagreb: Professor Rukavina Ana Staljvenic, ${ }^{*}$ Dr Jadranka Sertic, Dr Tomislav Babic and Dr Branka Ribaric.

Finland: National Public Health Institute, Department of Biochemistry, Helsinki: Professor Christian Ehnholm, ${ }^{*}$ Veikko Salomaa; National Public Health Institute, Department of Epidemiology and Health Promotion, Helsinki: Professor Jaakko Tuomilehto; Research Institute of Public Health, University of Kuopio: Professor Jukka T Salonen.

France: Centre de Médecine Préventive, Vandoeuvre-lesNancy: Professor Gérard Siest, ${ }^{*}$ Dr Sophia Visvikis, ${ }^{*}$ Dr Françoise Schiele, Dr Monique Vincent-Viry, Dr Bernard Herbeth, Dr Catherine Sass, Dr Aksam Merched, Dominique Aguillon, Mickael Maurice and the laboratory staff of the Centre; Institut National de la Santé et de la Recherche Médicale, Unité 258, Hôpital Broussais, Paris: Dr Laurence Tiret; Institut Pasteur de Lille, Lille: Professor Jean-Charles Fruchart, Dr Jean Dallongeville.

Germany: Medizinische Klinik, Universitäts-Krankenhaus Eppendorf, Hamburg: Dr Ulrike Beisiegel,* Central laboratory, University Hospital, Freiburg: Dr Winfried März.

Greece: The University of Crete, School of Medicine, Department of social Medicine, Heraklion: Professor Anthony Kafatos, ${ }^{*}$ Dr Joanna Moschandreas.

Italy: Clinical Chemistry, Legnano Hospital, LegnanoMilano: Dr Paolo Brambilla, ${ }^{*}$ IRCCS Ospedale San Raffaele, Clinical Molecular Biology Laboratory, Milano: Dr Maurizio Ferrari, Dr ssa Stefania Stenirri; Department of Neurology, Milano: Dr Massimo Franceschi; di Ricerca per le Malattie 
Cronico Degenerative, Università di Milano, Ospedale di Monza: Dr Marco Ferrari.

Macedonia: Clinic of Neurology, Faculty of Medicine, Skopje: Dr Angel Mitrevski.*

Portugal: Unidade de Quimica Clinica, Instituto Nacional de Saude, Lisbon: Dr Maria do Carmo Martins, ${ }^{*}$ Maria Odete Rodrigues, Maria Isabel Albergaria, Maria Liseta Alpendre.

Spain: Programa Cronicat, Institute of Health Studies, Barcelona: Dr Susanna Sans, ${ }^{*}$ Paluzie Guillem, Balanã Lluisa and Inãki Pérez; Unitat Recerca Lipids i Arteriosclerosi, Facultat de Medecina, Hospital de Sant Joan, Universitat
Rovira i Virgili, Reus: Dr Luis Masana, Dr Josep Ribalta, Dr Pilar Dra Martinez, Dr Jose Maria Olive.

United Kingdom: Department of Epidemiology and Public Health, The Queen's University of Belfast, Belfast, Northern Ireland: Professor Alun Evans, ${ }^{*}$ Dr John Yannell; Department of Medicine, The Queen's University of Belfast, Belfast, Northern Ireland: Dr D McMaster; Department of Pathological Biochemistry, Royal Infirmary, University of Glasgow, Glasgow, Great Britain: Professor James Shepherd.

Yugoslavia: Faculty of Pharmacy, Department of Medical Biochemistry, Belgrade: Prof Marina Stojanov.*

*Principal investigator. 